\title{
RESENHAS
}

\section{Identidades e conflitos antilusitanos}

\section{Lúcia Maria Bastos P. Neves}

RIBEIRO, Gladys Sabina. A liberdade em construção. Identidade nacional e conflitos antilusitanos no Primeiro Reinado. Rio de Janeiro: FAPERJ/Relume Dumará, 2002. 402 p.

Nas últimas décadas do século XX, especialmente a partir dos anos oitenta, com os processos de redemocratização da América Latina, a temática da cidadania política converteu-se em referência obrigatória não só para os debates políticos, como também para as discussões acadêmicas. Combinada a outros conceitos - tais como Estado, nação e democracia - essa preocupação levou ao surgimento de novas indagações numa perspectiva histórica, direcionadas em particular para os momentos fundadores desses países, ou seja, para os processos de independência das antigas colônias da América espanhola e portuguesa. Não mais cabiam nem a visão de um processso contínuo e linear, que teria forjado uma consciência nacio- nal desde o descobrimento até o século XIX, culminando com o rompimento dos laços das colônias com suas respectivas metrópoles; nem aquela que inseria exclusivamente a dinâmica metrópole/colônia nos circuitos da acumulação primitiva do capital, identificando-se as independências como o resultado da crise final do sistema colonial. Tornava-se necessário esmiuçar valores, comportamentos, atitudes e práticas, tanto políticas quanto culturais, através das quais os indivíduos, agrupados em novas formas de sociabilidade, rompiam, ou não, com os círculos privados de poder para constituir uma política pública, de modo a fazer triunfar uma nova legitimidade — a da nação e a do povo soberano. Debruçar-se sobre as independências passava a representar doravante, por conseguinte, analisar também essa configuração de poderes que começava a dar forma e sentido às idéias da nação e do cidadão, sem cair nas armadilhas colocadas 
pela visão nacionalista simplista gerada pela historiografia oitocentista e absorvida por muitos estudiosos posteriores. No entanto, como advertiu François-Xavier Guerra, em seu estudo sobre modernidade e independência nas sociedades hispânicas, um dos problemas cruciais nas Américas era construir, a partir de uma mesma "nacionalidade" — fosse hispânica, fosse portuguesa naçôes separadas e distintas. Nessa ótica, salientar conflitos implicava igualmente buscar identidades.

No Brasil, a historiografia não deixou de seguir por essa nova senda da pesquisa, resultando em trabalhos diversos, quase sempre oriundos de estudos realizados em programas de pós-graduação. Distintos problemas explicativos, relacionados ao próprio movimento de emancipação, como também aos períodos subseqüentes, em que se processou a definição do Império do Brasil, vieram à luz. A reincidência da temática não esgotou o debate. Ao contrário, abriu um leque de possibilidades, que permitiu repensar o processo de emancipação política, inserido na dinâmica mais profunda do complexo jogo de oposiçóes entre Antigo Regime e Modernidade, a partir de toda uma nova produção historiográfica, marcada pe- las abordagens da história social, da história cultural e pela história política renovada.

Entre esses novos estudos, insere-se o livro de Gladys Sabina Ribeiro, originalmente sua tese de doutorado, apresentada ao Programa de Pós-graduação em História da Universidade de Campinas, em 1997. Como a autora destaca em seu próprio prefácio, o objetivo é a discussão do processo de "formação identitária da nação", tomando como ponto de partida a questão da emancipação do Brasil, em 1822, e como ponto de chegada a abdicação de Pedro I, em 1831, fato considerado como o da verdadeira Independência, pois significou a "liberdade total do jugo português”. Nesse movimento, as rivalidades nacionais e raciais, que eram, até então, amenizadas pelo discurso de laços de "irmandade", vieram à tona, gerando conflitos de toda ordem, acentuando as diferenças entre brasileiros e portugueses, na medida em que tais conceitos passaram a ser politicamente construídos, a fim de fornecer uma identidade ao país recémcriado.

Sem visar a uma narração dos eventos políticos do período, o trabalho prende-se a uma abordagem da problemática social vivenciada 
pelos homens de época, em que a mescla de episódios políticos com conflitos sociais pretende levantar novas questões sobre o cenário da Independência e, mais profundamente, sobre a formação de uma identidade nacional. Ao estabelecer uma ligação direta entre os acontecimentos de março de 1831 e aqueles pertinentes ao movimento constitucional de 26 de fevereiro de 1821 e seus desdobramentos posteriores na Corte, a autora procura mostrar que, para além da simples dicotomia de uma luta nacional entre portugueses e brasileiros, existia uma tensão mais profunda e latente, revelada pela participação da "gente de cor" nas ruas do Rio de Janeiro, cujo caráter era racial e de classe. Ao lutarem contra a escravidão, essa população miúda opunha-se aos brancos, portugueses ou luso-descendentes em sua maioria, e indicava seu anseio de liberdade, identificada pela autora apenas a uma concepção de autonomia individual. Assim, a causa da "Liberdade do Brasil" converte-se na "Causa Nacional".

Nesse percurso, Gladys Ribeiro valeu-se, além do conhecimento de uma ampla bibliografia específica sobre o tema, de um rico e diversificado conjunto de fontes, demonstrando uma pesquisa exaustiva, que incluiu fontes oficiais (legislação, editais, ofícios, registros, requerimentos, correspondências entre órgãos governamentais, falas do trono, representaçóes, dados estatísticos e processos judiciais), a imprensa da época, memórias e coleções manuscritas relacionadas a diversos fundos, como por exemplo, o da Junta do Comércio e o do Desembargo do Paço. Nesse conjunto, destaca-se uma documentação inédita ou ainda insuficientemente trabalhada, essencial para a análise, constituída pelos processos de seqüestro de bens dos portugueses, pelos termos de adesão à Independência e à Constituição, além do amplo corpus oferecido pelos códices da Intendência de Polícia. Ao mesmo tempo, seguindo as pistas fornecidas por alguns trabalhos pioneiros, como os de Maria Beatriz Nizza da Silva e de Cecília Salles de Oliveira, a pesquisadora debruçou-se sobre alguns folhetos e panfletos políticos, assim como sobre os jornais do período. É através desse manancial inesgotável sobretudo que ela procura reconstituir o cenário da emancipação do Brasil e dos anos subseqüentes, esmiuçando não só os conflitos entre brasileiros e portugueses, mas também aqueles entre camadas diversas da população, com destaque para a 
atuação dos forros e escravos, que se julgavam, em sua ótica, co-partícipes dessa luta pela liberdade. Sob esse ângulo, examinar o antilusitanismo significa para a autora apreender igualmente as diferentes formas e vivências da liberdade, acentuando as divergências e rivalidades que opunham esses estratos aos brancos tanto no mercado de trabalho, em sua luta diária pela sobrevivência, quanto na busca por espaços políticos no círculo privado de poder que a Corte continuava a representar.

O livro estrutura-se em torno de três longos capítulos. Em primeiro lugar, examina o processo de emancipação brasileiro, para destacar, especialmente no decorrer do ano de 1821 e dos primeiros meses de 1822 , as incertezas que o caracterizaram em relação ao futuro do Brasil e à idéia de uma ruptura total, que permanecia indefinida para os grupos políticos das elites. Em sua interpretação, é somente após o Grito do Ipiranga, tomado mais como marco do que a convocação da Assembléia Constituinte ou os manifestos de agosto, que se tentou convencer o povo e a plebe da justeza da ação que fez raiar "a liberdade no horizonte do Brasil”. Em seguida, concentra sua atenção na elaboração de uma "certa identida- de nacional" nos primeiros anos do Império, que acabou por definir, sem restringi-los à qualificação de cidadania pelo local de nascimento, o "ser brasileiro" em oposição ao "ser português", enquanto conceitos politicamente construídos, tanto no âmbito da Corte, quanto na esfera da diplomacia. Nessa linha, o estrangeiro, mais especificamente o português, era o inimigo natural, que cabia vigiar e controlar através de uma série de normas e leis. Paralelamente, no entanto, o português, por jurar fidelidade à causa brasileira, também aparecia como o "adotivo", gerando ambigüidades, que marcaram os anos iniciais do Império e orientaram a definição da questão dos direitos de cidadania.

O segundo capítulo, por meio de uma análise criteriosa de inúmeros dados estatísticos sobre a entrada de portugueses no Brasil, Gladys Sabino Ribeiro traz uma importante contribuição para o estudo da imigração lusa nesses primeiros anos do Império, aspecto pouco considerado, ou, algumas vezes, até mesmo negado pela historiografia. A partir da naturalidade, idade, estado civil, profissão, emerge o perfil do imigrante lusitano, que integrava, no centro da multicolorida Corte, uma cidade de rostos brancos: a "Cida- 
dela Portuguesa", situada entre as freguesias de São José e da Candelária e delimitada pelas ruas Direita e da Quitanda e dos Ourives e das Violas. Esses indivíduos, em sua maioria, vinham para o Brasil impulsionados pela miséria de sua terra natal, mas passavam a exercer um papel relevante no mercado de trabalho, disputando oportunidades de trabalho com as camadas mais humildes, compostas na maioria por forros, pardos e mulatos. Permaneciam, porém, antes de tudo, brancos, contribuindo para o "embranquecimento" da população e, conseqüentemente, na visão da época, para seu progresso e civilização. Portanto, em meio à cidade que chamava a atenção dos viajantes pela pele negra da maioria de seus habitantes, que compunham, segundo Mary Karasch, a maior população escrava urbana das Américas entre 1808 e 1850 , surgia uma "verdadeira trincheira", na qual se desenrolavam as rixas entre portugueses natos e homens de cor, na disputa cotidiana por seus espaços de sobrevivência na Corte. O conhecido episódio das "garrafadas", em 1831, constituiu uma das explosóes desse confronto, em que brasileiros, escravos e libertos, invadiram o território da "Cidadela portuguesa" em nome da "nacionalida- de" e da "cidadania", identificadas uma vez mais com a causa do Brasil. Nessa perspectiva, os conflitos do período assumem dois traços básicos - tanto eram confrontos raciais quanto nacionais.

A última parte do livro aprofunda essas tensões e conflitos, analisando seus desdobramentos no âmbito da política oficial e no cotidiano para portugueses e brasileiros, incluídos no último termo não só descendentes luso-brasileiros, como também os pardos, mestiços e escravos. De fato, tais rivalidades manifestavam-se em diversos campos: no exército, entre os soldados portugueses ou estrangeiros, uma vez que, em regra, os primeiros eram preferidos para ocuparem os postos de comando; na burocracia administrativa, cujos cargos eram disputados entre lusos e brasileiros, embora ministros de Estado, oficiais, magistrados, deputados, inclusive o próprio imperador fossem, em sua origem, portugueses e tendessem a preferir seus conterrâneos; no círculo imediato do imperador, no qual a predominância de elementos portugueses acendia a desconfiança de um projeto absolutista para o novo país; por fim, nas camadas mais humildes da população, em função da concorrência exercida no mercado 
de trabalho pelo português imigrante de baixa renda. Nesse capítulo, através da análise dos diversos significados de "liberdade" que foram construídos a partir dos interesses e anseios dos não-brancos em relação aos portugueses e aos brasileiros, membros das elites, retoma-se igualmente a questão da definição da nacionalidade e da cidadania brasileira, o que faz ressaltar que a argumentação toma a questão racial como crucial para compreender o complexo jogo de idealização do que significava ser brasileiro naquele momento.

A obra, sem dúvida, oferece novas perspectivas de análise. Em primeiro lugar, ao destacar o papel exercido pelos portugueses na formação da identidade brasileira. Embora houvesse, de início, uma tendência a construir tal identidade em oposição a tudo que era português, fazendo José de Alencar ainda afirmar, no prefácio a Sonhos d'ouro (1872), que o "povo que chupa o caju, a manga, o cambucá e a jabuticaba" não podia "falar uma língua com igual pronúncia e o mesmo espírito do povo que sorve o figo, a pêra, o damasco e a nêspera”, as atitudes, na realidade, eram muito mais ambíguas, revelando uma curiosa oscilação entre a imitação e a rejei- ção do "ser português". Afinal a tradição e a cultura portuguesa encontravam-se enraizadas nas instituições, no cotidiano e nas mentes do Brasil, realimentadas por constantes levas de imigrantes, ainda que vistos depreciativamente. Em segundo lugar, ao salientar a participação da plebe nos movimentos políticos entre 1821 e 1831, contribuindo mais uma vez para desterrar a visão da história oficial de uma passividade do povo brasileiro. Por fim, ao situar o conceito de liberdade, ainda que discutível, enquanto uma concepção fundamental para se compreender a linguagem política daquela época. A liberdade em construção, portanto, revela-se um livro oportuno para servir de ponto de partida para novas indagaçóes em torno da questão da identidade nacional e dos conflitos sociais que marcaram os primeiros anos do Império do Brasil. Afinal, foi o divórcio entre o pais oficial das elites políticas e econômicas e o país real da massa excluída que levou o Brasil a trilhar um longo e penoso caminho, que ainda hoje continua a percorrer, em busca de sua própria identidade e de um direito de cidadania com que dotar todos os seus habitantes. 